\title{
Processing of Epidermal Glucosylceramides Is Required for Optimal Mammalian Cutaneous Permeability Barrier Function
}

\author{
Walter M. Holleran, * 8 Yutaka Takagi, *5 Gopinathan K. Menon, *5 Gunter Legler, " Kenneth R. Feingold, **|l and Peter M. Elias * * \\ Departments of ${ }^{*}$ Dermatology and ${ }^{\ddagger}$ Medicine, University of California School of Medicine, San Francisco, California 94143 ; \\ ${ }^{\S}$ Dermatology and "Medical Services, Veterans Affairs Medical Center, San Francisco, California 94121; \\ and "Institut für Biochemie, Universität Köln, 5000 Cologne 1, Federal Republic of Germany
}

\begin{abstract}
The interstices of the mammalian stratum corneum contain lipids in a system of continuous membrane bilayers critical for the epidermal permeability barrier. During the transition from inner to outer stratum corneum, the content of polar lipids, including glucosylceramides, decreases while ceramide content increases. We investigated whether inhibition of glucosylceramide hydrolysis would alter epidermal permeability barrier function. Daily topical applications of bromoconduritol B epoxide ( $\mathrm{BrCBE}$ ) to intact murine skin selectively inhibited $\beta$-glucocerebrosidase, increased glucosylceramide content of stratum corneum with ceramide content remaining largely unchanged, and caused a progressive, reversible decrease in barrier function. Histochemistry of inhibitor-treated epidermis revealed persistence of periodic acid-Schiff-positive staining in stratum corneum cell membranes, consistent with retention of hexose moieties. Electron microscopy of inhibitor-treated samples revealed no evidence of toxicity or changes in the epidermal lipid delivery system. However, immature membrane structures persisted in the intercellular spaces throughout the stratum corneum, with reappearance of mature membrane structures progressing outward from the lower stratum corneum upon termination of BrCBE. Finally, the induced barrier abnormality was not reversed by coapplications of ceramide. These data demonstrate that glucosylceramide hydrolysis is important in the formation of the epidermal permeability barrier, and suggest that accumulation of glucosylceramides in stratum corneum intercellular membrane domains leads to abnormal barrier function. (J. Clin. Invest. 1993.91:1656-1664.) Key words: ceramides $\bullet$ epidermis $\bullet \beta$-glucocerebrosidase • $\beta$-glucosidase $\bullet$ sphingolipids $\bullet$ stratum corneum
\end{abstract}

\section{Introduction}

Sphingolipids are important components of the mammalian permeability barrier (1-3), and their synthesis in the epidermis is critical for barrier maintenance $(4,5)$. In addition to accumulation of sphingolipids during the final stages of stratum corneum differentiation, other marked changes in lipid composition occur, the importance of which are not well understood. A general elimination of polar lipids, including glucosyl-

Address reprint requests to Dr. Walter M. Holleran, Dermatology Service (190), Veterans Affairs Medical Center, 4150 Clement Street, San Francisco, Ca 94121 .

Received for publication 15 July 1992 and in revised form 20 October 1992.

The Journal of Clinical Investigation, Inc.

Volume 91, April 1993, 1656-1664 ceramides ( $\mathrm{GlcCer})^{1}$ and phospholipids, is accompanied by an increase in free ceramides $(1,2,6)$, suggesting the activity of hydrolytic enzymes. A number of lipid catabolic enzymes, including sphingomyelinase, phospholipase $A$, triacylglycerol hydrolase $(7,8)$, steroid sulfatase $(9)$, as well as $\beta$-glucosidase $(10,11)$ have been localized to the sites where these transformations occur. Moreover, many of these enzymes have been colocalized with the epidermal lamellar body $(12,13)$, which is the delivery mechanism for most of these enzymes and their lipid substrates to the stratum corneum (reviewed in reference 14). Secretion of lamellar body contents results in the segregation of lipids and hydrolytic enzymes to the intercellular spaces of the stratum corneum $(7,8,12)$. Subsequently, a series of transformations in membrane structure occur, resulting in the formation of the basic lamellar membrane unit characteristic of the stratum corneum of terrestrial mammals $(15,16)$.

In addition to the biochemical and structural gradients described above, other circumstantial evidence suggests that the conversion of GlcCer to ceramide may be important for the maintenance of optimum barrier function. In both mucosal epithelia (17), and in the epidermis of marine cetaceans (18), both of which have less competent barriers than epidermis, the ratio of glucosylceramides to ceramides remains high. Moreover, $\beta$-glucosidase levels are lower in oral mucosa than in the epidermis of the same species (19). Whereas $\beta$-glucosidase activity has been quantitated previously in a number of epidermal preparations (20-27), we recently demonstrated that the bulk of this activity is $\beta$-glucocerebrosidase ( $\beta$-GlcCer'ase ) and that it is localized largely to the outer epidermis and stratum corneum (11). Although these prior studies suggest that extracellular processing of glycosphingolipids may be important for the development of barrier integrity, proof of this hypothesis has been lacking.

In order to directly test the hypothesis that extracellular sphingolipid processing is necessary for barrier maintenance, we applied an inhibitor of $\beta$-GlcCer'ase, bromoconduritol B epoxide ( $\mathrm{BrCBE} ; 28-30$ ), topically to intact skin, and found that this agent caused a progressive, reversible alteration in barrier integrity. Abnormal barrier function was associated with enzyme inhibition, enhanced sphingolipid synthesis, and accumulation of GlcCer in the stratum corneum. Moreover, these biochemical changes were accompanied by persistence of immature membrane structures in the stratum corneum. These results strongly support the hypothesis that extracellular

1. Abbreviations used in this paper: $\mathrm{BrCBE}$, bromoconduritol $\mathrm{B}$ epoxide (1,2-anhydro-6-bromo-6-deoxy-myo-inositol); $\mathrm{CBE}$, conduritol-B epoxide (1,2-anhydro-myo-inositol); dNJM, deoxynojirimycin; GlcCer, glucosylceramide; $\beta$-GlcCer'ase, $\beta$-glucocerebrosidase; HPTLC, high performance thin layer chromatography; $4 \mathrm{MU}$, 4-methylumbelliferone; TEWL, transepidermal water loss. 
processing of sphingolipids is required for the maintenance of the epidermal barrier in terrestrial mammals (31).

\section{Methods}

Materials. 4-Methylumbelliferone(4MU), $4 \mathrm{MU}-\alpha$-D-glucoside, $4 \mathrm{MU}$ - $N$-acetyl- $\beta$-D-glucoside, 4 MU- $\beta$-D-glucoside, $\alpha$-hydroxy- and non-hydroxyceramides (IV and III, respectively), $\alpha$-hydroxy- and non-hydroxygalactocerebrosides (I and II, respectively), deoxynojirimycin (dNJM), and sodium taurocholate were obtained from Sigma Chemical Co. (St. Louis, MO). 4-MU- $\alpha$-L-fucopyranoside, $4 \mathrm{MU}-\beta$-D-galactopyranoside, $4 \mathrm{MU}-\alpha$-D-mannopyranoside, and $4 \mathrm{MU}$-2-acetamido-2deoxy- $\beta$-D-glucopyranoside were obtained from Koch-Light Laboratories Ltd. (Colnbrook, England). Conduritol B epoxide (CBE) and bromoconduritol were obtained from Toronto Research Chemicals, Inc. (Toronto, Canada), and $\mathrm{BrCBE}$ was prepared as previously described (32). Bio-Rad Protein Assay Kit and BSA were obtained from Bio Rad Laboratories (Richmond, CA). High-performance thin layer chromatography (HPTLC) plates (Silica gel 60) were obtained from Merck (Darmstadt, FRG). All solvents were of reagent or HPLC grade.

Animals. Hairless male mice $(\mathrm{Hr} / \mathrm{Hr})$ were purchased from Simonsen Laboratories (Gilroy, CA), and fed Purina mouse diet and water ad libitum. All animals were eight-12 weeks old at the time of study. Barrier function was assessed as transepidermal water loss (TEWL), and was measured at various time points with an electrolytic water analyzer (Meeco, Warrington, PA), as described in detail previously $(4,5,33)$. Water loss measurements are obtained over a small area of skin $\left(0.5 \mathrm{~cm}^{2}\right)$, recorded in parts per million $/ 0.5 \mathrm{~cm}^{2}$ per h over background. At each timepoint, three to five readings are performed on each flank (both treated and untreated), with six to eight animals in each test group.

Preparation of epidermal homogenates. Epidermal sheets were obtained from hairless mice by first removing whole skin samples from authorized animals and exposing samples to dry heat $\left(60^{\circ} \mathrm{C}, 60 \mathrm{~s}\right)$, followed by gentle scraping with a scalpel blade. All subsequent steps were performed at $4^{\circ} \mathrm{C}$, unless otherwise noted. Epidermal sheets were homogenized in 10 vol of PBS (with $0.1 \mathrm{mM}$ PMSF) using a Polytron ( $15 \mathrm{~s}, \times 3$ bursts), and sonication ( $35 \%, 10 \mathrm{~s} \times 2$ bursts). Protein concentrations were measured using the Bradford procedure (34) with bovine serum albumin (BSA) serving as the standard.

Preparation of stratum corneum. Epidermal sheets first were separated from dermis by soaking in calcium/magnesium-free Dulbecco's phosphate-buffered saline solution (PBS-CMF), containing $10 \mathrm{mM}$ EDTA for $1.0 \mathrm{~h}$ at $37^{\circ} \mathrm{C}$. Epidermal sheets then were floated for $1.0 \mathrm{~h}$ at $25^{\circ} \mathrm{C}$ in $0.5 \%$ trypsin solution (in PBS-CMF), at which point the trypsin solution was changed. After $30 \mathrm{~min}$ the tissue was gently sonicated for $10 \mathrm{~min}$ and rinsed with distilled water, and each sheet of stratum corneum was trimmed to the same size $(\approx 19 \times 25 \mathrm{~mm})$.

Epidermal $\beta$-glucosidase assay. Our assay methods for $\beta$-glucosidases are modified from that of Mier and van den Hurk (35), as reported previously (11). Briefly, assays were performed at $37^{\circ} \mathrm{C}$ in citrate-phosphate buffer (pH 5.6) containing $5 \mathrm{mM}(0.54 \%)$ sodium taurocholate, with $0.5 \mathrm{mM} 4 \mathrm{MU}-\beta$-D-glucoside as substrate, and a 60 min reaction time. Enzyme solutions in assay buffer $(50 \mu 1)$ were preheated in siliconized glass culture tubes, and reactions initiated by the addition of $50 \mu 1$ of substrate solution in assay buffer. Reactions were terminated by adding $1.25 \mathrm{ml}$ of $200 \mathrm{mM}$ carbonate-bicarbonate buffer $(\mathrm{pH} \mathrm{10.5)}$. The fluorescence $(\mathrm{ex}=360 \mathrm{rm}, \mathrm{em}=450 \mathrm{rm})$ was measured with a fluorescence spectrophotometer (Perkin-Elmer Corp., Norwalk, CT; model 204). A standard 4MU solution (0-300 nM) in carbonate-bicarbonate buffer was used for calibration of each assay.

Inhibition of $\beta$-GlcCer'ase activity. The inhibition of $\beta$-GlcCer'ase was first determined for each of four inhibitors (CBE, BrCBE, bromoconduritol, and dNJM; see Fig. 1) in vitro using epidermal extracts. Inhibitors were preincubated with enzyme for $15 \min \left(37^{\circ} \mathrm{C}\right)$ before assay mitigation by substrate addition. Inhibitor concentrations in the assay mixture were varied from $10^{-9}$ to $10^{-2} \mathrm{M}$ and estimates of apparent IC $_{\text {so's }}$ were obtained. The specificity of $\beta$-GlcCer'ase inhibition was then tested by determining the effects of $\mathrm{BrCBE}$ on the activity of other glucosidases. First, the $\mathrm{pH}$ dependence (3.2-7.0) was determined for the hydrolysis of each of the following 4-MU derivatives; $\alpha$-D-glucoside, $\beta$-D-glucoside, $\alpha$-mannoside, $\alpha$-L-fucoside, $\beta$-D-galactoside, 2 -acet-

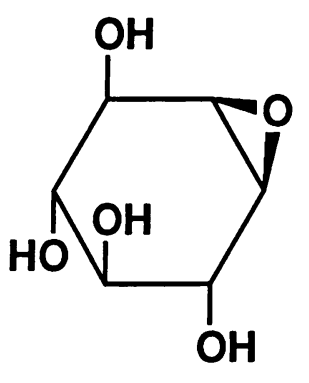

CONDURITOL B EPOXIDE CBE

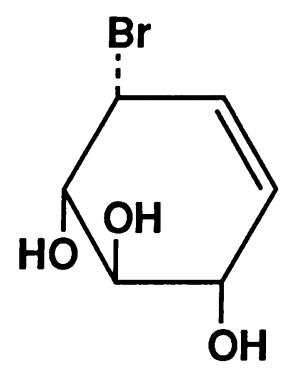

BROMOCONDURITOL

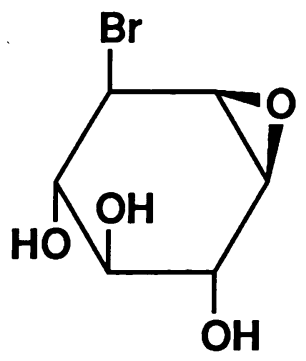

BROMOCONDURITOL B EPOXIDE

BrCBE

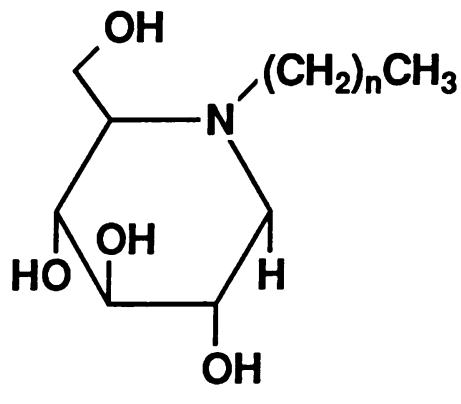

\section{DEOXY-NOJIRIMYCIN dNJM}

Figure 1. Structures of $\beta$-glucosidase inhibitors. Three conduritol derivatives are shown, with variation due to the presence or absence of epoxide $\left(\mathrm{C}_{1}-\mathrm{C}_{6}\right)$, and /or $\mathrm{Br}$ substitutions $\left(C_{5}\right)$ of the myoinositol ring. Deoxynojirimycin displays unique features, including a withinring nitrogen and an alkyl chain substitution. 
amide-2-deoxy- $\beta$-D-glucoside, $N$-acetyl- $\beta$-D-glucoside. $\operatorname{BrCBE}$ (at $10^{-2}, 10^{-4}, 10^{-6} \mathrm{M}$ ) was then added to each assay at the respective $\mathrm{pH}$ optima.

A single dose of each inhibitor was then applied topically to mouse epidermis (15-20 $\mu \mathrm{l}$ of a $25 \mu \mathrm{mol} / \mu 1$ solution) in vehicle (propylene glycol:ethanol; 70:30, vol/vol). After 1 and $24 \mathrm{~h}$, the animals were killed, and the epidermis was separated from dermis, as above. The epidermis was homogenized and $\beta$-glucosidase activity was measured, as described as above.

In other studies, each of the inhibitors $(15-20 \mu 1$ of $25 \mu \mathrm{mol} / \mu 1$ in vehicle) was applied once daily for several days to intact mouse skin $\left(\sim 5 \mathrm{~cm}^{2}\right)$, and TEWL measurements were recorded at five locations on each of 3-10 mice. After 5-8 d of daily inhibitor application, samples were taken for analysis of lipid content, and light and/or electron microscopy (see below). The same volume of vehicle was applied daily to a separate cohort of control animals.

Lipid extraction, fractionation, and quantitation. Epidermal sheets were obtained from hairless mouse skin by exposure to dry heat (as above), while stratum corneum sheets were prepared as described above. Lipids were extracted by a modification of the Bligh-Dyer method $(2,6)$, dried, weighed, and stored in chloroform at $-70^{\circ} \mathrm{C}$ until use. For separation and quantitation of individual sphingolipid species, we employed a modification of the HPTLC method of Ponec et al. (36), as described recently $(4,5)$. After the final solvent run, the dried plates were dipped in charring solution adapted from Ponec (37) ( $1.5 \%$ cupric sulfate in acetic acid/sulfuric acid/orthophosphoric acid/distilled $\mathrm{H}_{2} \mathrm{O}$ (50:10:10:95, vol), dried $\left(40^{\circ} \mathrm{C}, 10 \mathrm{~min}\right.$.), and then charred at $180^{\circ} \mathrm{C}$ for $5 \mathrm{~min}$. The plates were scanned with a variable wavelength scanning densitometer (Camag, Muttenz, Switzerland) and the lipid fractions quantitated by comparison to known standards run in duplicate simultaneously for each fraction. Integration was performed using CATS II software (Camag).

Sphingolipid synthesis. The effect of $\mathrm{BrCBE}$ on sphingolipid synthesis was assessed in vivo after intraperitoneal injections of $\left[{ }^{3} \mathrm{H}\right]-\mathrm{H}_{2} \mathrm{O}(20$ $\mathrm{mCi} / 0.2 \mathrm{ml}$ ) administered $1 \mathrm{~h}$ after either BrCBE treatment or vehicle application. $2 \mathrm{~h}$ after the injection, blood samples were taken and the animals were killed. Whole skin was excised $\left(\sim 8 \mathrm{~cm}^{2}\right)$ from each flank (BrCBE-treated and -untreated sides), heated for $60 \mathrm{~s}\left(60^{\circ} \mathrm{C}\right)$, and the epidermis was separated from the dermis with gentle scraping, as described above. Samples were blotted dry, weighed, minced, and immediately placed into screw-cap glass test-tubes containing BlighDyer solvents, and total lipid extracts were prepared, as described above. The lipid components were separated by HPTLC, as described previously $(4,5)$, visualized using fluorescence to UV-A light after 8-anilino-1-naphthalene-sulfonic acid staining (2), identified by cochromatography with known standards, scraped into scintillation vials, and counted by liquid scintillation spectrometry. Incorporation of tritium into total ceramide and glucosylceramide fractions was determined. Using the specific activity of ${ }^{3} \mathrm{H}-\mathrm{H}_{2} \mathrm{O}$ in serum samples from each animal, results were presented as $\mu$ moles product formed $/ \mathrm{mg}$ of epidermal wet weight over the $2 \mathrm{hr}$. incubation, as described previously $(4,5,38,39)$.

Histochemistry. Fresh, full-thickness skin samples were obtained before treatment, and at various time points after daily applications of $\mathrm{BrCBE}$ and vehicle. Samples were fixed in buffered formalin, paraffinembedded, and sectioned $(5 \mu \mathrm{m})$. Parallel sections were stained with periodic acid-Schiff, hematoxylin/eosin, and colloidal iron. Sections then were examined and photographed with a Leitz Ortholux II microscope.

Transmission electron microscopy. At various time points following treatment with the protocols described above, full-thickness skin biopsies were obtained from euthanized animals, minced to $<0.5 \mathrm{~mm}^{2}$, and fixed in modified Karnovsky's fixative overnight. Samples then were postfixed in both $0.2 \%$ ruthenium tetroxide, utilizing a recently described protocol (16), and $2 \%$ aqueous osmium tetroxide, both containing $1.5 \%$ potassium ferrocyanide in the dark. After fixation, all samples were dehydrated in graded ethanol solutions, and embedded in an Epon-epoxy mixture (40). Thin sections were examined, with or without further contrasting with lead citrate, in a Zeiss $10 \mathrm{~A}$ electron microscope, operating at $60 \mathrm{kV}$.

Statistical analysis. Statistical evaluation of data was performed using either a two-tailed Student's $t$ test or a paired $t$ test.

\section{Results}

\section{Effect of BrCBE on epidermal $\beta$-glucosidase activity}

To address the biochemical basis for the effects of $\mathrm{BrCBE}$ in the epidermis, we first determined the inhibition of $\beta$-glucocerebrosidase activity by $\mathrm{BrCBE}$ and its chemically related and unrelated analogues (Fig. 1). The apparent $I_{50}$ values for BrCBE, CBE, bromoconduritol, and dNJM obtained under the assay conditions employed were approximately 0.1, 5.0,60, and $3.0 \mu \mathrm{M}$, respectively (Fig. 2). The 50 -fold lower value for $\mathrm{BrCBE}$ is consistent with published results (29). Moreover, a single topical application of $\mathrm{BrCBE}$ to intact murine epidermis resulted in a dose- and time-dependent inhibition of $\beta$-glucosidase activity. A dose of $375 \mu \mathrm{mol} / 5 \mathrm{~cm}^{2}$ resulted in over $90 \%$ inhibition at $1 \mathrm{~h}$, with activity recovering to $50 \%$ of control by 24 hours (Table I). Consistent with their $\mathrm{IC}_{50}$ values, single topical applications of equimolar doses of CBE, bromoconduritol, and $\mathrm{dNJM}$ resulted in less inhibition of epidermal $\beta$-glucosidase activity $(40,41$; and $0 \%$ at $1 \mathrm{~h}$, respectively). These enzymatic studies demonstrate significant inhibition of epidermal $\beta$-glucosidase by a single topical application of $\mathrm{BrCBE}$.

The specificity of $\mathrm{BrCBE}$ for $\beta$-glucosidase over other glucosidases then was determined in epidermal homogenates. Assays were performed with and without added BrCBE using the following 4-MU substrate derivatives: $\beta$-D-glucoside, $\alpha$-D-glucoside, $\alpha$-mannoside, $\alpha$-fucoside, $\beta$-D-galactoside, 2 -acetamido-2-deoxy- $\beta$-D-glucoside, and $N$-acetyl- $\beta$-D-glucoside. The results demonstrate that $\mathrm{BrCBE}$ specifically inhibits the hydrolysis of $4 \mathrm{MU}-\beta$-D-glucoside, exhibiting no effects (up to $10 \mu \mathrm{M}$ ) on any of the other glycoside substrates (Fig. 3).

\section{Effect of repeated topical applications of $B r C B E$ on epidermal barrier function}

We next investigated whether chronic inhibition of $\beta$-glucosidase would alter epidermal barrier function. Daily applications of $\mathrm{BrCBE}$ to intact murine epidermis resulted in progressive disruption of the epidermal permeability barrier reaching maximal levels by five to seven days, and plateauing thereafter (Fig. 4). Although the levels of water loss were moderately increased ( TEWL $\leq 0.6 \pm 1.0 \mathrm{mg} / \mathrm{cm}^{2}$ per $\mathrm{h}$ ), they are nearly 10 -fold less than produced by physical and chemical forms of barrier disruption, such as acetone-extraction or tape-stripping (33). Cessation of topical BrCBE led to a gradual normalization of TEWL rates over $5 \mathrm{~d}$, with the majority of improvement occurring within the first $48 \mathrm{~h}$ (Fig. 4). Moreover, coapplication of ceramides did not diminish the BrCBE effect on TEWL. Finally, daily applications of CBE, bromoconduritol and dNJM had no effect on epidermal permeability barrier at the highest dose possible based on the solubility of these compounds in the vehicle.

\section{Effects of topical BrCBE on sphingolipid synthesis and content}

Epidermal synthesis. In order to determine whether the observed effects of $\mathrm{BrCBE}$ on the barrier were due to inhibition of $\beta$-glucocerebrosidase activity, we next measured the incorporation of $\left[{ }^{3} \mathrm{H}\right] \mathrm{H}_{2} \mathrm{O}$ into glucosylceramides and ceramides in 


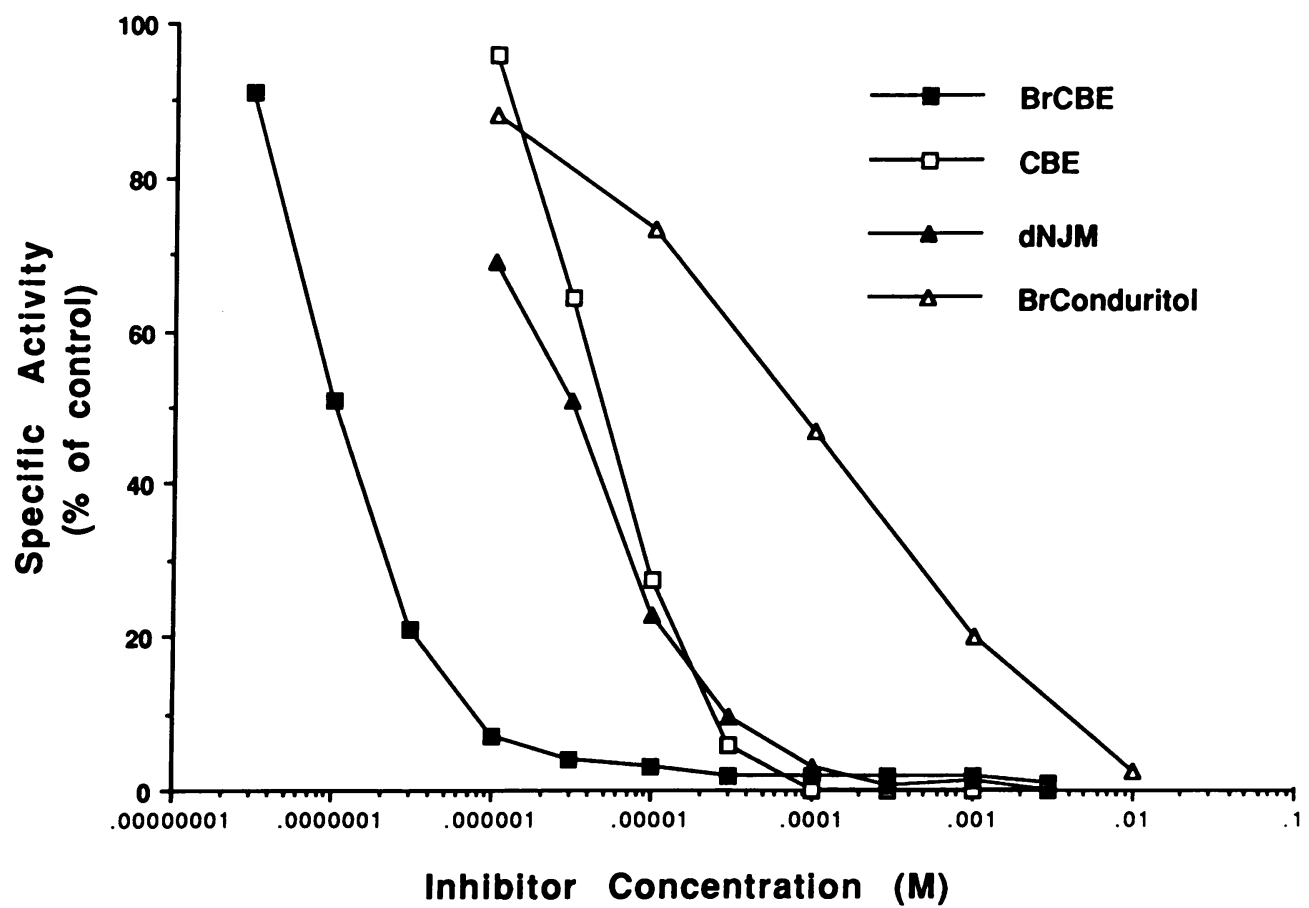

Figure 2. Inhibition of epidermal $\beta$-glucosidase activity. Representative plot of $\beta$-glucosidase activity as a percent of the control activity vs. inhibitor concentration $(\mathrm{M})$. Data are presented as the mean of triplicate determinations, with SD omitted for clarity ( $\mathrm{SD} \leq 3 \%$ for all values). Epidermal extracts ( see Methods) were used as the enzyme source. The relative $\mathrm{IC}_{50}$ 's obtained for $\mathrm{BrCBE}, \mathrm{CBE}$, dNJM, and bromoconduritol were 0.1 , 5.0, 3.0 and $60 \mu \mathrm{M}$, respectively. whole epidermis of BrCBE-treated animals. As shown in Fig. 5, the incorporation of $\left[{ }^{3} \mathrm{H}\right] \mathrm{H}_{2} \mathrm{O}$ into epidermal glucosylceramides was increased $(82 \% ; P<0.05)$ in inhibitor-treated compared with control animals, suggesting decreased glucosylceramide hydrolysis due to $\mathrm{BrCBE}$. In contrast, the incorporation of $\left[{ }^{3} \mathrm{H}\right] \mathrm{H}_{2} \mathrm{O}$ into ceramides was unchanged in the BrCBEtreated animals. The observation that inhibitor-treated tissues demonstrate accelerated, rather than depressed incorporation rates indicates that these changes are not likely due to generalized toxicity.

Stratum corneum sphingolipid content. We next determined whether the altered pattern of $\left[{ }^{3} \mathrm{H}\right] \mathrm{H}_{2} \mathrm{O}$ incorporation into epidermal sphingolipids resulted in changes in stratum corneum sphingolipid distribution. Inhibitor-treated stratum corneum showed a significant increase in glucosylceramide content in comparison to controls, with the ceramide content

Table I. Effect of BrCBE on Epidermal $\beta$-Glucocerebrosidase Activity

\begin{tabular}{|c|c|c|c|}
\hline Time $\pm \operatorname{BrCBE}(n)$ & Activity & $\begin{array}{l}\text { Percentage } \\
\text { of control }\end{array}$ & Significance ${ }^{\ddagger}$ \\
\hline & $\underset{\text { protein }^{*}}{\text { nmol/min }}$ & & \\
\hline $0 \mathrm{~h}-(12)$ & $1.19 \pm 0.01$ & $100 \%^{\S}$ & - \\
\hline $1 \mathrm{~h}-(6)$ & $1.20 \pm 0.06$ & & \\
\hline$+(9)$ & $0.10 \pm 0.03$ & $8.7 \%$ & $P \leq 0.001$ \\
\hline $24 h-(6)$ & $1.27 \pm 0.07$ & & \\
\hline$+(6)$ & $0.65 \pm 0.03$ & $51.0 \%$ & $P \leq 0.005$ \\
\hline
\end{tabular}

Effect of BrCBE on epidermal $\beta$-glucocerebrosidase activity. Enzyme activity was measured in vitro before (time 0 ) and after BrCBE-treatment $\left(375 \mu \mathrm{mol} / 5 \mathrm{~cm}^{2}\right)$ at 1 and $24 \mathrm{~h}$. ${ }^{*}$ Data represents the mean $\beta$-glucosidase activity $( \pm \mathrm{SD})$; ${ }^{\ddagger}$ Significance: BrCBE-treated $(+)$ vs. untreated (-); ${ }^{\S}$ Activity at time 0 set to $100 \%$. remaining largely unchanged (Fig. 6). CBE, bromoconduritol, and $\mathrm{dNJM}$ did not alter epidermal sphingolipid content. These data show that the increased incorporation of $\left[{ }^{3} \mathrm{H}\right] \mathrm{H}_{2} \mathrm{O}$ into epidermal glucosylceramides resulting from $\mathrm{BrCBE}$-treatment is reflected in an increased glucosylceramide content in the stratum corneum.

\section{Structural alterations induced by $B r C B E$ treatment}

As described previously (41), the stratum corneum membrane domains in control epidermal samples do not stain positively for glycoconjugates with either periodic acid-Schiff for neutral hexose residues, or colloidal iron for acidic polysaccharide residues. In contrast, in samples treated with $\mathrm{BrCBE}$ for five days, the stratum corneum displayed increased PAS staining intensity while the colloidal iron staining of the epidermis remained unchanged relative to control samples (data not shown). These histochemical results are consistent with increased glucosylceramide content in the stratum corneum.

In order to ascertain the subcellular basis for the $\mathrm{BrCBE}$ effect on permeability barrier function, we next examined control vs. inhibitor-treated epidermis by electron microscopy (Figs. 7 and 8). In samples treated for three days with BrCBE, at a time when barrier function is still largely intact (c.f., Fig. 4), a striking abnormality in lamellar bilayer unit structures first became apparent in the lower stratum corneum. Elongated lamellar body-derived sheets (Fig. $7 \mathrm{~B}$ ), with the same substructure and dimensions as initially secreted lamellar body pleated sheets (42), replaced the normal membrane unit structure (Fig. $8 \mathrm{~A}$ ). In contrast, lamellae in the outer layers still displayed the normal mature unit structure (Fig. $7 A$ ). In samples treated for seven successive days with $\mathrm{BrCBE}$, there was no evidence of cytotoxicity; i.e., nuclei, mitochondria, and other organelles appeared unaffected (not shown). Moreover, the internal structure of epidermal lamellar bodies (Fig. $7 \mathrm{D}$, inset) appeared comparable to controls, as did the secreted contents of lamellar bodies at the stratum granulosum-stratum corneum 


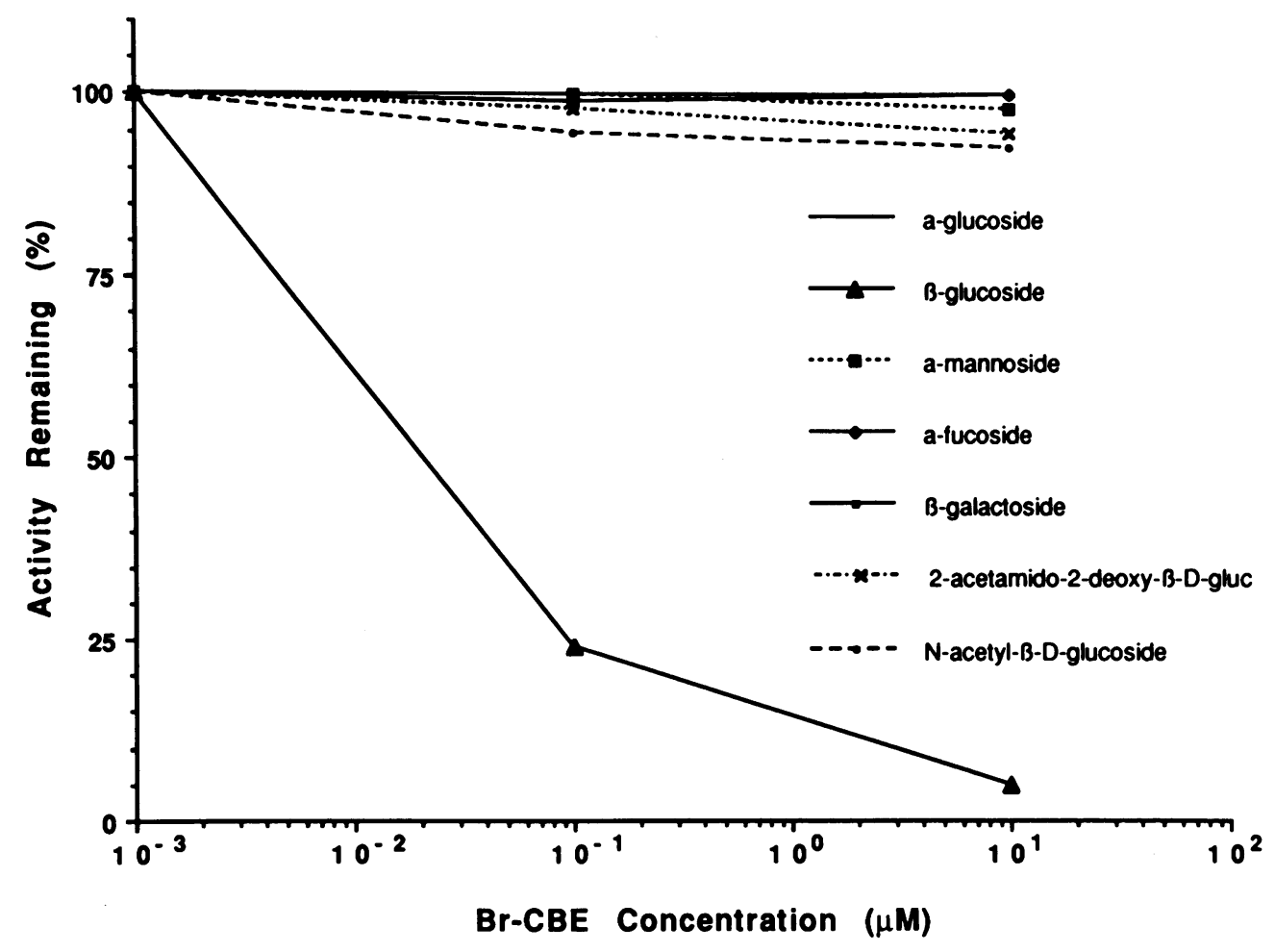

Figure 3. Specificity of $\mathrm{BrCBE}$ for $\beta$-glucosidase -inhibitory effect of $\mathrm{BrCBE}$ on the hydrolysis of various 4-MU glycoside substrates (see Methods). At the $\mathrm{pH}$ optima for each substrate, BrCBE was added to the assay with the epidermal extract as the enzyme source. Data represent the mean of triplicate determinations, with error bars omitted for clarity ( $S D \leq 4 \%$ for all values; $\mathrm{a}=\alpha$ ). interface (Fig. $7 \mathrm{D}$ ). In contrast to the 3-d samples, however, the abnormality in lamellar bilayer unit structure was now evident in the intercellular spaces at all levels of the stratum corneum (Fig. $7 \mathrm{C}$ ). Moreover, these elongated, unprocessed sheets were loosely packed and often separated by clefts; i.e., nonlamellar domains (Fig. $7 C$, asterisks). Finally, when treated animals are allowed to revert by cessation of topical inhibitor applications for two days, the membrane abnormali- ties initially persist in the mid-to-outer stratum corneum, while newly formed, mature, lamellar basic unit structures appear in the lower stratum corneum (Fig. $8 A$ ). By $6 \mathrm{~d}$ after cessation of treatment, the mature lamellar unit structure is evident throughout the stratum corneum (Fig. $8 \mathrm{~B}$ ). These results show first, that persistence of glucosylceramides into the stratum corneum provokes alterations in intercellular lamellar bilayer unit structure. Second, these results show that full expres-

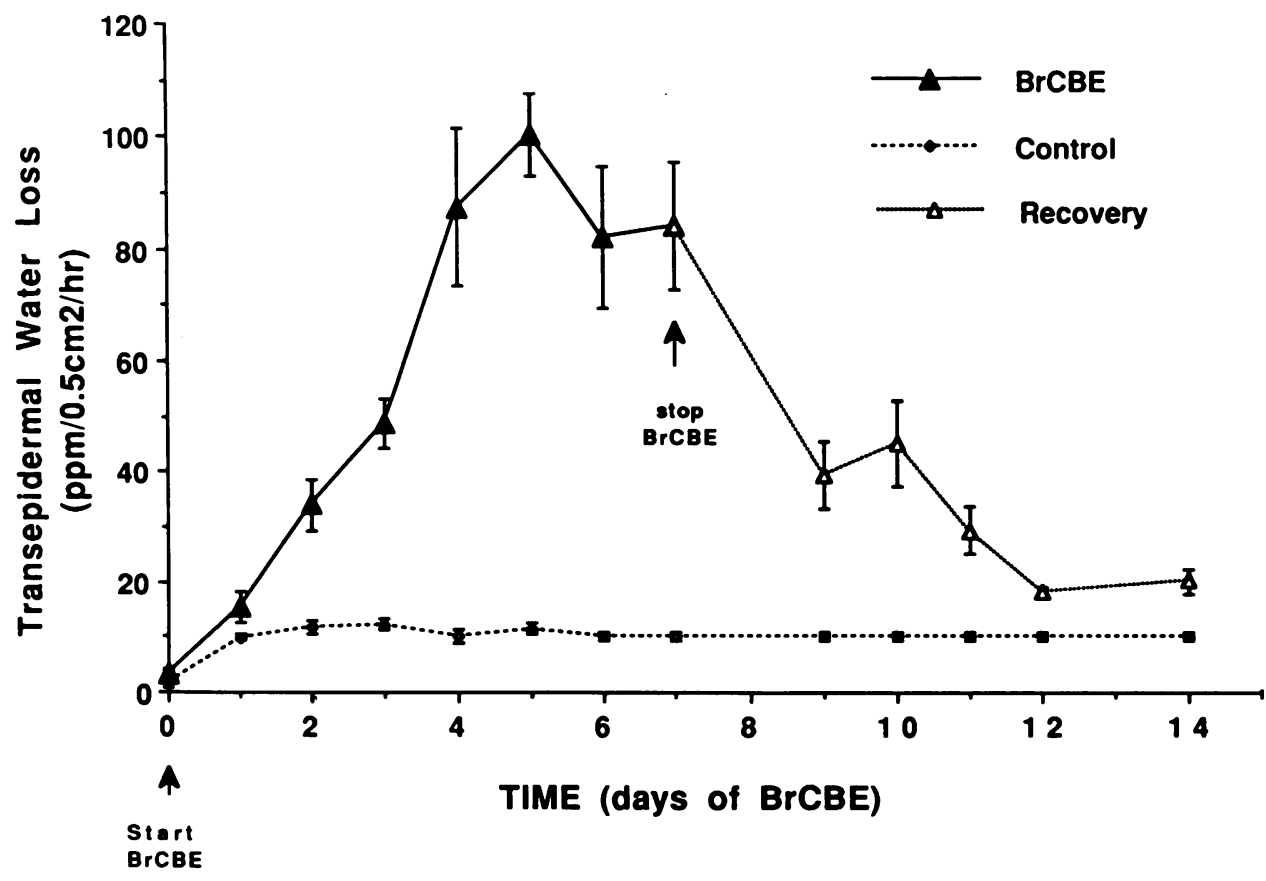

Figure 4. Effect of repeated topical BrCBE applications on epidermal barrier function (transepidermal water loss). Animals were treated daily with either BrCBE ( 375 $\mu \mathrm{mol} / 5 \mathrm{~cm}^{2}$ ) or vehicle (propylene glycol/ethanol, 70:30 vol/vol).

TEWL measurements were made daily immediately before the next application. Each value represents the mean $( \pm$ SEM $)$ of at least three TEWL readings on each of six to eight animals $(n \geq 18)$. Barrier dysfunction reached maximum levels at five days $(P<0.001)$, with no further deterioration upon continued treatment. In contrast, treatment with the vehicle alone did not effect barrier function (controls). When BrCBE was stopped at day 7 (arrow), barrier recovery was complete after an additional 5-7 d. 


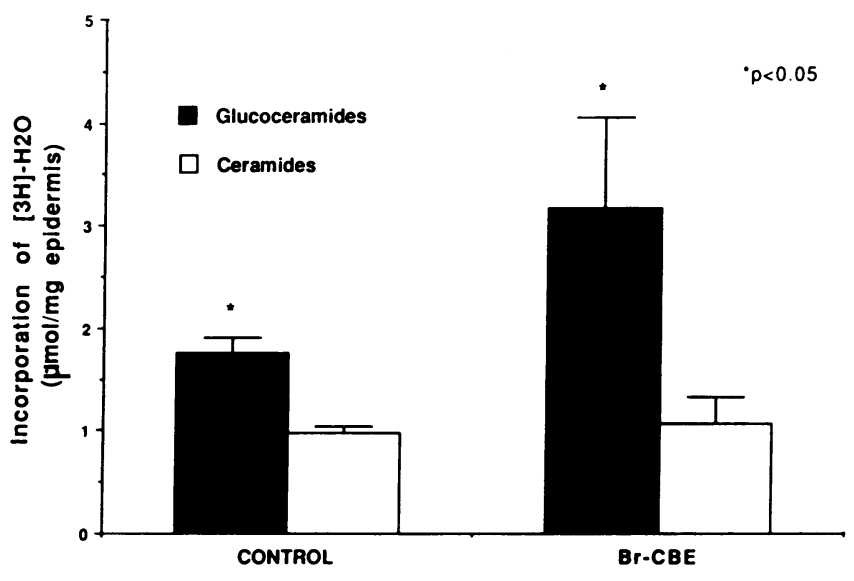

Figure 5. Effect of $\mathrm{BrCBE}$ on $\left[{ }^{3} \mathrm{H}\right]-\mathrm{H}_{2} \mathrm{O}$ incorporation into sphingolipids. $1 \mathrm{~h}$ after topical treatment with either vehicle (control) or $\mathrm{BrCBE},\left[{ }^{3} \mathrm{H}\right]-\mathrm{H}_{2} \mathrm{O}$ was injected intraperitoneally. $2 \mathrm{~h}$ later, epidermis was isolated, lipids were extracted and radioactivity quantitated (see Methods). Data are presented as the mean incorporation of tritium over 2 hrs. from triplicate determinations $( \pm S D)$. Whereas, increased glucosyl-ceramide synthesis was observed in $\mathrm{BrCBE}$-treated epidermis $(P<0.05$ vs. vehicle-treated controls $)$, incorporation into ceramides remained unchanged.

sion of the barrier abnormality correlates with replacement of mature membrane structures by incompletely processed "immature" lamellae at all levels of the stratum corneum interstices.

\section{Discussion}

The formation of the stratum corneum in the epidermis of terrestrial mammals is accompanied by striking changes in lipid composition and distribution (reviewed in references 14 and 43). During the final stages of this differentiation process, a lipid mixture enriched in ceramides, cholesterol, and free fatty acids replaces the phospholipid-neutral lipid mixture present in the subjacent nucleated layers $(1,2,6)$. Moreover, these lipids become segregated within intercellular domains at the level of the stratum corneum (14). These changes in lipid composition can be attributed to two distinct cellular process. The first involves active de novo synthesis, which is sustained into the outer nucleated cell layer, the stratum granulosum (4446). Much of the newly synthesized sphingolipids and cholesterol are packaged in epidermal lamellar bodies, organelles enriched in these lipid species $(12,13)$, which provide the secretory mechanism for delivery of these lipids to the stratum corneum interstices (reviewed in reference 14). However, the lamellar body is not enriched in ceramides and free fatty acids, but rather in glycosphingolipids and phospholipids $(12,13)$. Thus, the second process results in the conversion of the glycosphingolipid-cholesterol-phospholipid mixture to the ceramide-cholesterol-free fatty acid mixture which emerges within the stratum corneum. This conversion is presumed to result from hydrolysis by a family of lipases and glycosidases that are co-packaged with lipids in the lamellar body $(7,8,12$, 13). Moreover, the co-deposition of lamellar body lipids and enzymes appears to be followed not only by the biochemical changes noted above, but also by parallel modulations in mem- brane structure that lead ultimately to the mature membrane structures that appear to mediate epidermal barrier function in terrestrial mammals $(8,42)$.

The present study provides the first direct evidence that the conversion of glucosylceramides to ceramides is a prerequisite for the maintenance of a competent permeability barrier in a terrestrial environment. Repeated topical applications of $\mathrm{BrCBE}$, a potent inhibitor of B-GlcCer'ase (28-30), to intact murine skin were accompanied by a progressive increase in TEWL, which plateaued after several days. Interestingly, chemically related and unrelated compounds (CBE, bromoconduritol, and $\mathrm{dNJM}$ ) inhibited $\beta$-glucosidase activity, but to a lesser degree. Chronic treatment with these compounds affected neither the sphingolipid distribution within the epidermis nor permeability barrier function. Thus, it is likely that the remaining epidermal enzyme activity ( $\sim 60 \%$ at $1 \mathrm{~h}$ after treatment) was sufficient to allow ongoing hydrolysis of glucosylceramide. Similar findings were reported during the development of an animal model for Gaucher's disease, where glucosylceramide accumulation was observed only when inhibition of $\beta$-GlcCer'ase activity was maintained below $12-16 \%$ of control values (47). Moreover, patients with decreased $\beta$-GlcCer'ase activity, do not demonstrate Gauchers disease symptoms unless activity is less than $\sim 20 \%$ of normal. Heterozygous patients, despite lower than normal enzyme activity, do not show evidence of disease.

The barrier abnormality induced by $\mathrm{BrCBE}$ is likely caused by increased glucosylceramide secondary to inhibition of $\beta$ glucocerebrosidase and not due to nonspecific toxicity because: First, $\mathrm{BrCBE}$ did not inhibit other closely related glucosidases, suggesting that the barrier abnormality is attributable to a selective inhibition of GlcCer'ase. Second, BrCBE treatment resulted in an accelerated, rather than a depressed incorporation of $\left[{ }^{3} \mathrm{H}\right] \mathrm{H}_{2} \mathrm{O}$ into glucosylceramide, with the increase in stratum corneum GlcCer content reflecting an inhibition of hydrolysis. Third, the effects of $\mathrm{BrCBE}$ on epidermal barrier function were reversible upon cessation of treatment. Fourth, chemi-

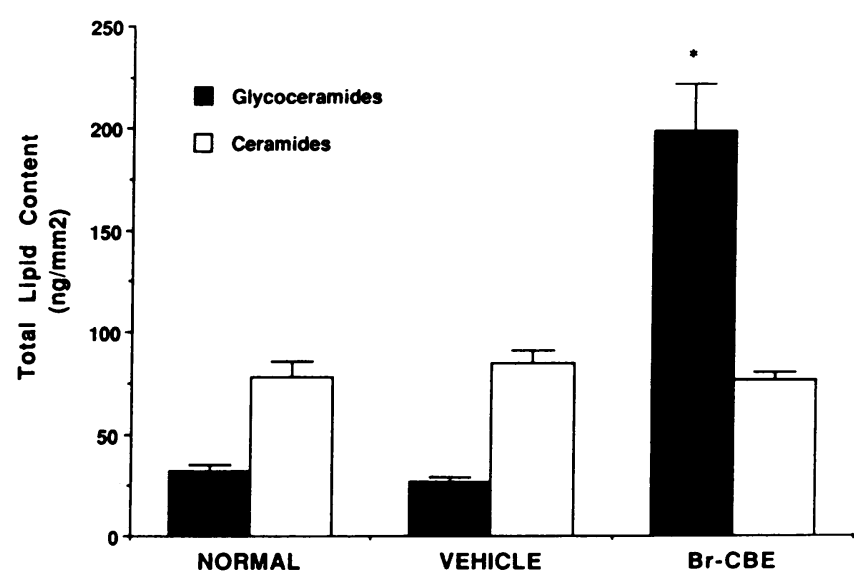

Figure 6. Effect of $\mathrm{BrCBE}$ on stratum corneum glucosylceramide and ceramide content: animals were treated daily with $\mathrm{BrCBE}$ for $5 \mathrm{~d}$, the stratum corneum was isolated, and the lipids were extracted and quantitated by HPTLC and densitometry (see Methods). Untreated and vehicle-treated animals served as controls. Results are presented as mean lipid weight per $\mathrm{mm}^{2}$ of epidermal surface area ( $\pm \mathrm{SEM} ; n$ $\geq 6$ for each value). BrCBE-treated animals demonstrated significantly higher levels of glucosylceramides $(P<0.005)$. 

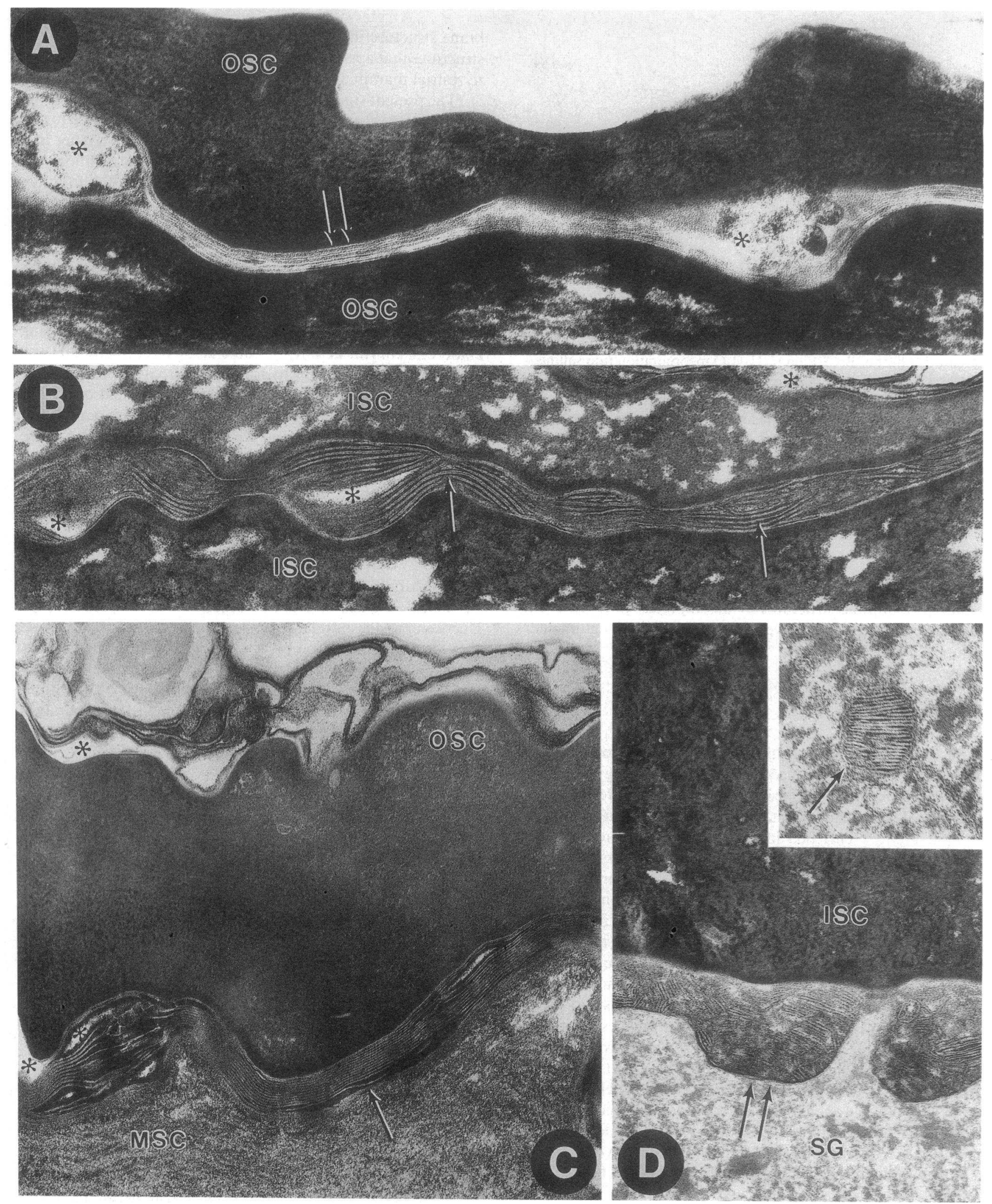

Figure 7. Ultrastructure of stratum corneum after BrCBE treatment. After $3 \mathrm{~d}$ of treatment, the outer stratum corneum (OSC) still displays intact lamellar basic unit structures $(A$, double arrows). However, the inner stratum corneum $(I S C)$ displays elongated, incompletely processed lamellar body derived sheets ( $B$, single arrows). After $7 \mathrm{~d}$ of treatment, all SC layers display incompletely processed lamellar body derived sheets $(C$, single arrow). Lamellar bodies $(D$, insert, arrow $)$ and their secreted contacts at the stratum granulosum-ISC interface display no abnormalities $(D$, double arrows $)$. Asterisks indicate sites of vehicle extraction and/or phase separation (42). MSC, mid-SC; $\mathrm{RuO}_{4} \mathrm{fixed} ;(A) \times 90,000$, $(B) \times 76,000,(C) \times 45,500,(D) \times 57,000$, inset $\times 71,000$. 

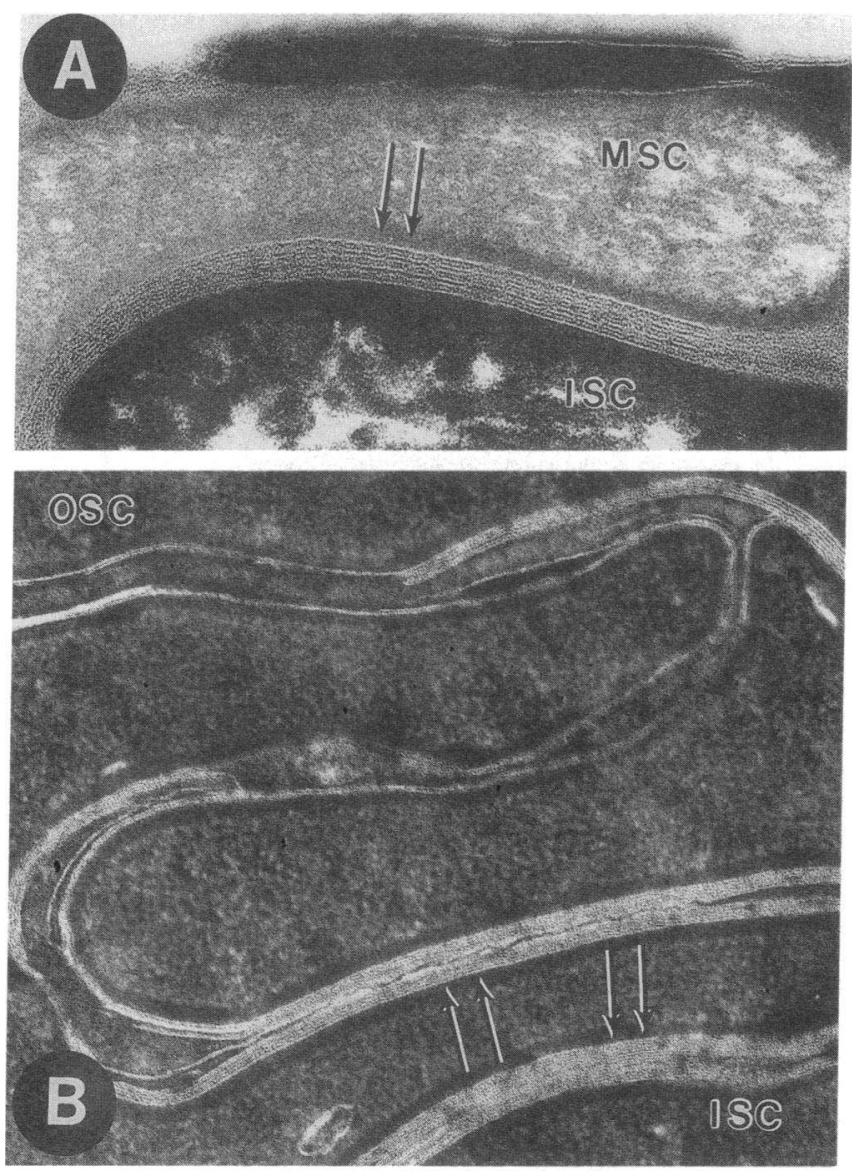

Figure 8. Ultrastructure of stratum corneum after cessation of $\mathrm{BrCBE}$ application. After $2 \mathrm{~d}(A)$, normal lamellar bilayers are apparent in the lower SC (double arrows). By $6 \mathrm{ds}(B)$, normal lamellar bilayers are present at all layers of the SC (double arrows). OSC, outer-SC; MSC, mid-SC; ISC, inner-SC; $\mathrm{RuO}_{4}$ fixed; (A) $\times 74,500$, (B) $\times 80,500$

cally-related chemicals which are less potent inhibitors of $\beta$ glucosidase, did not alter glucosylceramide content or produce an abnormality in barrier function. Fifth and finally, histochemical and ultrastructural studies revealed no evidence of inflammation or cytotoxicity in inhibitor-treated tissues. Since the $\beta$-glucosidase activity of the epidermis is primarily $\beta$ GlcCer'ase (11), the barrier abnormality appears to stem from specific inhibition of this enzyme.

The inhibition of $\beta$-GlcCer'ase could produce the barrier defect by two distinct biochemical mechanisms; i.e., through a decrease in ceramide generation from glucosylceramides or through an accumulation of glucosylceramides. Our studies clearly point to the latter mechanism as the principle cause of the barrier abnormality. Whereas the total ceramide content of stratum corneum remained normal, both the incorporation of $\left[{ }^{3} \mathrm{H}\right] \mathrm{H}_{2} \mathrm{O}$ into epidermal glucosylceramides, and the stratum corneum glucosylceramide content were significantly increased by $\mathrm{BrCBE}$ treatment. Moreover, coapplications of ceramide with $\mathrm{BrCBE}$ did not prevent emergence of the barrier abnormality, further suggesting that precursor accumulation rather than lack of product is the cause of the barrier abnormality. Thus, the biochemical basis for the barrier abnormality in this model appears to be an accumulation of glucosylceramides rather than decreased generation of ceramides. Whether com- pensatory mechanisms for increasing the ceramide content of the stratum corneum are operative during $\mathrm{BrCBE}$ treatment, possibly through sphingomyelin hydrolysis, is currently under investigation.

The structural studies also provided insights into the mechanism whereby glucosylceramide accumulation induces the barrier abnormality. The intercellular bilayers in BrCBEtreated samples revealed elongated lamellar body sheets in parallel, loosely packed arrays, but no mature, lamellar basic membrane unit structures. The barrier abnormality appears to peak and plateau at a point when these immature membrane structures replace the basic membrane unit structures at all levels of the stratum corneum. Mature lamellar unit structures are characteristic of epidermis which exhibits an intact barrier, and they are replaced by immature structures both in occluded skin (42), and in the epidermis of marine cetaceans (18). It is noteworthy that in each of these situations, barrier requirements are far less stringent than in the terrestrial, air-exposed environment. Pertinently, glucosidase levels also are reportedly low in mucosal epithelia (19), and glucosylceramides accumulate in both mucosal epithelia (17) and cetacean epidermis (18). All of these data support the direct evidence presented here that extracellular glucosylceramide processing to ceramides is required for epidermal barrier competence in terrestrial mammals.

In summary, we have shown that the hydrolysis of glucosylceramides to ceramides is a requirement for epidermal permeability barrier function in terrestrial mammals. Topical applications of bromoconduritol B epoxide to intact skin inhibited $\beta$-glucocerebrosidase activity, accompanied by accelerated synthesis and accumulation of glucosylceramides in the epidermis. These biochemical changes were associated with the persistence of immature, lamellar body-derived membrane structures within the intercellular spaces of the stratum corneum.

\section{Acknowledgments}

These studies were supported by National Institutes of Health grants AR 19098, 39448, and 39639, the Medical Research Service, Department of Veterans Affairs. Yutaka Takagi was supported as a Visiting Scientist by Kao Corporation of Japan. Ms. Lisa Price assisted with the electron microscopy, while Mr. Bil Chapman and Ms. Sally Michael capably prepared the manuscript.

\section{References}

1. Gray, G. M., and H. J. Yardly. 1975. Different populations of pig epidermal cells: isolation and lipid composition. J. Lipid Res. 16:441-447.

2. Elias, P. M., B. E. Brown, P. Fritsch, J. Goerke, G. M. Gray, and J. White 1979. Localization and composition of lipids in neonatal mouse stratum granulosum and stratum corneum. J. Invest. Dermatol. 73:339-348.

3. Wertz, P. W., and D. T. Downing. 1982. Glycolipids in mammalian epidermis: structure and function in the water barrier. Science (Wash. DC). 217:12611262.

4. Holleran, W. M., K. R. Feingold, M. Mao-Qiang, W. N. Gao, J. M. Lee, and P. M. Elias. 1991. Regulation of epidermal sphingolipid synthesis by permeability barrier function. J. Lipid Res. 32:1151-1158.

5. Holleran, W. M., M. Mao-Qiang, G. K. Menon, P. M. Elias, and K. R. Feingold. 1991. Sphingolipids are required for mammalian barrier function: inhibition of sphingolipid synthesis delays barrier recovery after acute perturbation. J. Clin. Invest. 88:1338-1345.

6. Lampe, M. A., M. L. Williams, and P. M. Elias. 1983. Human epidermal lipids: Characterization and modulations during differentiation. J. Lipid Res. 4:131-140.

7. Menon, G. K., S., Grayson, and P. M. Elias. 1986. Cytochemical and biochemical localization of lipase and sphingomyelinase activity in mammalian epidermis. J. Invest. Dermatol. 86:591-597. 
8. Elias, P. M., G. K. Menon, S., Grayson, and B. E. Brown. 1988. Membrane structural alterations in murine stratum corneum: relationship to the localization of polar lipids and phospholipases. J. Invest. Dermatol. 91:3-10.

9. Elias, P. M., M. L. Williams, M. E. Maloney, J. A. Bonifas, B. E. Brown, S. Grayson, and E. H. Epstein, Jr. 1984. Stratum corneum lipids in disorders of cornification: steroid sulfatase and cholesterol sulfate in normal desquamation and the pathogenesis of recessive X-linked ichthyosis. J. Clin. Invest. 74:14141421.

10. Nemanic, M. K., J. S. Whitehead, and P. M. Elias. 1983. Alterations in membrane sugars during epidermal differentiation: visualization with lectins and role of glycosidases. J. Histochem. Cytochem. 31:887-897.

11. Holleran, W. M., Y. Takagi, G. Imokawa, S. Jackson, K. R. Feingold, and P. M. Elias. 1992. $\beta$-Glucocerebrosidase activity in murine epidermis: characterization and localization in relationship to differentiation. J. Lipid Res. 33:12011209.

12. Freinkel, R. K., and T. N. Traczyk. 1985. Lipid composition and acid hydrolase content of lamellar granules of fetal rat epidermis. J. Invest. Dermatol. 85:295-298.

13. Grayson, S., A. G. Johnson-Winegar, B. U. Wintroub, R. R. Isseroff, E. H Epstein, and P. M. Elias. 1985. Lamellar body-enriched fractions from neonatal mice: preparative techniques and partial characterization. J. Invest. Dermatol. 85:289-294.

14. Elias, P. M., and G. K. Menon. 1991. Structural and lipid biochemical correlates of the epidermal permeability barrier. Adv. Lipid Res. 24:1-26.

15. Madison, K. C., D. C. Swartzendruber, P. W. Wertz, and D. T. Downing 1987. Presence of intact intercellular lamellae in the upper layers of the stratum corneum. J. Invest. Dermatol. 88:714-718.

16. Hou, S. Y. E., A. K. Mitra, S. H. White, G. K. Menon, R. Ghadially, and P. M. Elias. 1991. Membrane structures in normal and essential fatty acid deficient stratum corneum: characterization by ruthenium tetroxide staining and x-ray diffraction. J. Invest. Dermatol. 96:215-223.

17. Squier, C. A., P. S. Cox, P. W. Wertz, and D. T. Downing. 1986. The lipid composition of porcine epidermis and oral epithelium. Arch. Oral Biol. 31:741747.

18. Menon, G. K., S. Grayson, B. E. Brown, and P. M. Elias. 1986. Lipokeratinocytes of the epidermis of a cetacean, (Phocena phocena): histochemistry, ultra structure, and lipid composition. Cell Tissue Res. 244:385-394.

19. Chang, F., P. W. Wertz, and C. A. Squier. 1991. Comparison of glycosidase activities in epidermis, palatal epithelium, and buccal epithelium. Comp Biochem. Physiol. 100B:137-139.

20. Ockerman, P. A. 1969. Acid hydrolases in human skin. Acta Dermat. Venereol. 49:139-141.

21. Goldberg, M. F., E. Cotlier, L. G. Fichenscher, K. Kenyon, R. Enat, and S. A. Borowsky. 1971. Macular cherry-red spot, corneal clouding, and $\beta$-galactosidase deficiency. Arch. Intern. Med. 128:387-398.

22. Ohkawara, A., K. M. Halprin, J. R. Taylor, and V. Levine. 1972. Acid hydrolases in the human epidermis. Br. J. Dermatol. 83:450-459.

23. Mier, P. D., and J. J. M. A. Van Den Hurk. 1975. Lysosomal hydrolases of the epidermis. I. Glycosidases. Br. J. Dermatol. 93:1-10.

24. Wolff, K., and E. Schreiner. 1970. Epidermal lysosomes. Electron microscopic-cytochemical studies. Arch. Dermatol. 101:276-286.

25. Nemanic, M. K., J. S. Whitehead, and P. M. Elias. 1983. Alterations in membrane sugars during epidermal differentiation: visualization with lectins and role of glycosidases. J. Histochem. Cytochem. 31:887-897.

26. Wertz, P. W., and D. T. Downing. 1989. $\beta$-glucosidase activity in procine epidermis. Biochim. Biophys. Acta. 1001:115-119.

27. Chang, F., P. W. Wertz, and C. A. Squier. 1991. Comparison of glycosidase activity in epidermis, palatal epithelium, and buccal epithelium. Comp. Biochem. Physiol. 100B:137-139.
28. Legler, G., and H. Liedtke. 1985. Glucosylceramidase from calf spleen Characterization of its active site with 4-n-alkylumbelliferyl $\beta$-glucosides and $\mathrm{N}$-alkyl derivatives of 1-deoxynojirimycin. Biol. Chem. Hoppe-Seyler. 366:11131122.

29. Dinur, T., K. M. Osiecki, G. Legler, S. Gatt, R. J. Desnick, and G. A Grabowski. 1986. Human acid $\beta$-glucosidase: Isolation and amino acid sequence of a peptide containing the catalytic site. Proc. Natl. Acad. Sci. USA. 83:16601664.

30. Legler, G., and E. Bieberich. 1988. Active site directed inhibition of a cytosolic $\beta$-glucosidase from calf liver by bromoconduritol B epoxide and bromoconduritol F. Arch. Biochem. Biophys. 260:437-442.

31. Holleran, W. M., Y. Takagi, K. R. Feingold, and P. M. Elias. 1992. Processing of glucosylceramides is required for maintenance of the permeability barrier in intact skin. Clin. Res. 40:73A. (Abstr.)

32. Legler, G. 1988. In Methods in Enzymology. W. B. Jacoby and M. Wilchek, editors. Academic Press, Inc., New York. 46:368-381.

33. Menon, G. K., K. R. Feingold, A. H. Moser, B. E. Brown, and P. M. Elias. 1985. De novo sterologenesis in the skin. II. Regulation by cutaneous barrier requirements. J. Lipid Res. 26:418-427.

34. Bradford, M. M. 1976. A rapid and sensitive method for the quantitation of microgram quantities of protein using the principle of protein-dye binding. Anal. Biochem. 72:248-254.

35. Mier, P. D., and J. J. M. A. van den Hurk. 1976. Lysosomal hydrolases of the epidermis. Br. J. Dermatol. 95:271-274.

36. Ponec, M. A., A. Weerheim, J. Kempenaar, A-M. Mommaas, and D. A. Nugteren. 1988. Lipid composition of cultured human keratinocytes in relation to their differentiation. J. Lipid Res. 29:949-961.

37. Ponec, M. 1991. Lipid metabolism in cultured keratinocytes. Adv. Lipid Res. 24:119-139.

38. Grubauer, G., K. R. Feingold, and P. M. Elias. 1987. Relationship of epidermal lipogenesis to cutaneous barrier function. J. Lipid Res. 28:746-752.

39. Grubauer, G., P. M. Elias, and K. R. Feingold. 1989. Transepidermal water loss: The signal for recovery of barrier structure and function. J. Lipid Res. 30:323-333.

40. McNutt, N. S., and W. L. Crain. 1981. Quantitative electron microscope comparison of lymphatic nuclear contours in mycosis fungoides and in benign infiltrates in the skin. Cancer. 47:163-166.

41. Elias, P. M., R. Orozco-Topete, M. A. Lampe, M. L. Williams, M. K. Nemanic, S. Grayson, and B. E. Brown. 1985. Methods in epidermal lipid research. In Methods in Skin Research. D. Skerrow and C. J. Skerrow, editors. Sussex, England. 381-405.

42. Menon, G. K., K. R. Feingold, and P. M. Elias. 1992. The lamellar body secretory response to barrier disruption. J. Invest. Dermatol. 98:209-219.

43. Yardley, H. J., and R. Summerly. 1981. Lipid composition and metabolism in normal and diseased epidermis. Pharmacol. Ther. 13:357-383.

44. Feingold, K. R., B. E. Brown, S. R. Lear, A. H. Moser, and P. M. Elias. 1983. Localization of de novo sterologenesis in mammalian skin. J. Invest. Dermatol. 81:365-369.

45. Monger, D. J., M. L. Williams, K. R. Feingold, B. E. Brown, and P. M. Elias. 1988. Localization of sites of lipid biosynthesis in mammalian epidermis. $J$. Lipid Res. 29:603-612.

46. Proksch, E., P. M. Elias, and K. R. Feingold. 1991. Localization and regulation of epidermal 3-hydroxy-3-methylglutaryl-coenzyme A reductase activity by barrier requirements. Biochim. Biophys. Acta. 1083:71-79.

47. Stephens, M. C., A. Bernatsky, V. Burachinsky, G. Legler, and J. N. Kanfer. 1978. The Gaucher mouse: differential action of conduritol B-epoxide, a reversibility of its effects. J. Neurochem. 30:1023-1027. 